\title{
Research Communication Neutrophilic Cell-Free Exudate Induces Antinociception Mediate by the Protein S100A9
}

\author{
Rosana L. Pagano, ${ }^{1}$ Mario Mariano, ${ }^{2,3}$ and Renata Giorgi ${ }^{1}$ \\ ${ }^{1}$ Laboratory of Pathophysiology, Butantan Institute, Avenue Vital Brazil 1500, São Paulo 05503-900, Brazil \\ ${ }^{2}$ Discipline of Immunology, Federal University of São Paulo, Rua Botucatu 862, São Paulo 04023-062, Brazil \\ ${ }^{3}$ Discipline of Immunology, Paulista University, Rua Dr Bacelar 1212, São Paulo 04026-002, Brazil
}

Received 18 April 2006; Revised 26 June 2006; Accepted 27 June 2006

\begin{abstract}
Calcium-binding protein S100A9 (MRP-14) induces antinociceptive effect in an experimental model of painful sensibility and participates of antinociception observed during neutrophilic peritonitis induced by glycogen or carrageenan in mice. In this study, the direct antinociceptive role of the protein S100A9 in neutrophilic cell-free exudates obtained of mice injected with glycogen was investigated. Mice were intraperitoneally injected with a glycogen solution, and after 4, 8, 24, and 48 hours, either the pattern of cell migration of the peritoneal exudate or the nociceptive response of animals was evaluated. The glycogen-induced neutrophilic peritonitis evoked antinociception 4 and 8 hours after inoculation of the irritant. Peritoneal cell-free exudates, collected in different times after the irritant injection, were transferred to naive animals which were submitted to the nociceptive test. The transference of exudates also induced antinociceptive effect, and neutralization of S100A9 activity by anti-S100A9 monoclonal antibody totally reverted this response. This effect was not observed when experiments were made 24 or 48 hours after glycogen injection. These results clearly indicate that S100A9 is secreted during glycogen-induced neutrophilic peritonitis, and that this protein is responsible by antinociception observed in the initial phase of inflammatory reaction. Thus, these data reinforce the hypothesis that the calcium-binding protein S100A9 participates of the endogenous control of inflammatory pain.
\end{abstract}

Copyright (c) 2006 Rosana L. Pagano et al. This is an open access article distributed under the Creative Commons Attribution License, which permits unrestricted use, distribution, and reproduction in any medium, provided the original work is properly cited.

\section{INTRODUCTION}

Neutrophils, monocytes, and macrophages secret a variety of biologically active products involved in distinct pathophysiologic types of response. That is the case of the calciumbinding proteins S100A8 and S100A9 [1], both members of the family of the S100 proteins [2], which are expressed in differentiating cells of the myeloid lineage, in mature neutrophils and monocytes, but absent in normal tissue macrophages and lymphocytes $[3,4]$.

The S100A8/A9 proteins comprise $45 \%$ of the total proteins in the cytosol of neutrophils and $1 \%$ in monocytes [5], and can be found in a complex form called calprotectin [6]. S100A8 and S100A9 proteins are also described as $\mathrm{p} 8$ and $\mathrm{p} 14$ [7], L1 light and heavy chain [8], calgranulin A and B [9], and MRP-8 and MRP-14 [10], respectively. Under inflammatory conditions and/or upon calcium mobilization they are translocated from the cytosol to the cytoskeleton and to cell plasma membrane $[11,12]$. It has been demonstrated that both proteins are secreted by activated monocytes via a tubulin and PKC-dependent pathway [13]. In addition, the heterodimer of these proteins binds arachidonic acid with high affinity in a calcium-dependent manner [14].

Although little is known about the biological function of S100A8/A9, it has been demonstrated that in vitro the calprotectin has an antimicrobial effect on several micro organisms $[6,15]$, and induces apoptosis of various tumour cells or normal fibroblasts in a zinc-reversible manner $[16,17]$. S100A8/A9 complex is found in high concentrations in body fluids of patients with acute and chronic diseases such as chronic bronchitis, cystic fibrosis, and rheumatoid arthritis [18], making this complex a useful biomarker of inflammatory diseases [19]. An anti-inflammatory effect of this complex in a model of adjuvant-induced arthritis in the rat was reported [20], suggesting a possible extra cellular role for these proteins.

Independent expression and functioning of S100A9 protein have also been observed $[10,21]$. This protein regulates neutrophil adhesion to fibrinogen, selectively activates the $\beta_{2}$ integrin, Mac-1 [22] and deactivates BCG-activated peritoneal macrophages [23]. We have demonstrated a marked antinociception effect of S100A9 in a model of inflammatory 
pain [24]. Further, antinociception was detected in the course of acute neutrophilic peritonitis induced by glycogen and carrageenan, which were reverted by the treatment of animals with a monoclonal antibody anti-S100A9, suggesting that neutrophils in acute inflammation down-regulate the nociceptive response via S100A9 activity [24, 25]. Recently, we demonstrated that the C-terminus of S100A9 murine inhibits the spreading and phagocytic activities of adherent peritoneal cells [26], cells involved in the nociceptive response during the model of abdominal contortions in mice [27]. Based on these data, in the present study we investigated the antinociceptive effect of the neutrophilic cell-free exudate induced by glycogen, and the role of the calciumbinding protein S100A9 in this effect.

\section{MATERIALS AND METHODS}

\section{Animals}

Outbred male mice from the Swiss strain, weighing 20-25 g, were used throughout this study. The animals were maintained under controlled light (12/12 hours) and temperature $\left(22 \pm 2^{\circ} \mathrm{C}\right)$ with free access to food and water. Throughout the experiments, the animals were managed using the principles and guidelines published by the Committee for Research and Ethical Issue of the International Association for Study of Pain [28].

\section{Glycogen-induced peritonitis}

Mice were intraperitoneally (IP) injected with $500 \mu \mathrm{L}$ of a $5 \%$ solution of oyster glycogen type II (Sigma, Mo, USA) prepared in sterile saline. Control animals were injected only with saline. After 4, 8, 24, or 48 hours of glycogen solution inoculation, mice were either sacrificed, in a $\mathrm{CO}_{2}$ chamber, to evaluation of the peritoneal fluid or submitted to the nociceptive test.

\section{Nociception evaluation by the writhing test}

The mouse writhing test used was based on the method of Koster et al [29]. The abdominal contortions resulting from intraperitoneal injection of acetic acid (0.6\%; Merck, Darmstadt, Germany) at a dosage of $60 \mathrm{mg} / \mathrm{Kg}$ (v/v) consist of contraction of the abdominal muscles with stretching of the hind limb. The number of abdominal contortions was counted cumulatively over a period of 20 minutes after acetic acid injection. The antinociceptive activity was expressed as the reduction in number of abdominal contortions in treated as compared to control animals, injected with saline or only with acetic acid.

\section{Inflammatory cells characterization and cell-free exudate collection}

Mice injected with glycogen solution or sterile saline, after different times, were sacrificed in a $\mathrm{CO}_{2}$ chamber and their peritoneal cavities washed with $5 \mathrm{~mL}$ of cold phosphate- buffered saline (PBS) pH 7.4. After a gentle massage of the abdominal wall, the peritoneal fluid was collected and the total and differential counts of leukocytes were determined. The leukocyte cell-free exudate supernatant was obtained from the peritoneal fluid after two individual centrifugations $\left(2000 \mathrm{rpm} / 10 \mathrm{~min}, 5^{\circ} \mathrm{C}\right)$. Supernatants assembled for each time and group of the treatment were frozen $\left(-20^{\circ} \mathrm{C}\right)$ and, in the moment of assay, were injected in naive animals ( $200 \mu \mathrm{L} /$ cavity) 30 minutes before of the evaluation of the antinociceptive activity.

\section{Monoclonal antibody ( $m A b)$}

Mouse mAb (IgG1) antihuman S100A9 (anti-MRP-14; BMA Biomedicals AG, Switzerland) and goat $\mathrm{mAb}$ antimouse IgG1 (Sigma, Mo, USA) were used.

\section{Adsorption of S100A9 of the inflammatory cell-free exudates}

$\mathrm{mAb}$ antimouse IgG1 $(1 \mathrm{mg} / \mathrm{mL})$ in carbonate buffer $(\mathrm{pH}$ 9.5) was distributed in wells of 96-well ELISA plates (100 $\mu \mathrm{L} /$ well) and incubated overnight at $4^{\circ} \mathrm{C}$. These solutions were removed and the wells were filled with $1 \%$ bovine seric albumine (BSA) in PBS $(200 \mu \mathrm{L} /$ well $)$ for 12 hours at $4^{\circ} \mathrm{C}$. The wells were washed (three times) with PBS followed by Twin $20(0.5 \%)$ in PBS (two times) and replaced with $200 \mu \mathrm{L}$ of supernatants obtained from the inflammatory cell-free exudate, after 4 or 8 hours of glycogen inoculation, previously incubated with antihuman S100A9 (mouse IgG1 isotype). The supernatants were adsorbed in triplicate on antimouse IgG1-coated wells in 2-hour intervals, and finally incubated on coated wells for 18 hours at $4^{\circ} \mathrm{C}$. These supernatants were frozen $\left(-20^{\circ} \mathrm{C}\right)$, and in the moment of assay were intraperitoneally injected in naive animals (200 $\mu \mathrm{L} /$ cavity), 30 minutes before the nociceptive test.

\section{Statistical analysis}

Results are expressed as mean \pm standard errors of means (SEM) and were compared by the Student $t$ test or by analysis of variance [30], followed by Duncan's test [31]. A probability level of less than .05 was taken as significant $(P<.05)$.

\section{RESULTS}

\section{Glycogen-induced leukocyte migration}

As we had previous evidence that neutrophils, via protein S100A9 (MRP-14), mediate the antinociceptive effect in a neutrophilic peritonitis induced by glycogen [24], we first decided to establish the leukocyte influx induced by the irritant. Results confirmed our data and showed that the IP injection of glycogen induced a significant number of polymorphonuclear cells in the peritoneal cavity of animals when compared with controls. The maximal number of these cells was observed 8 hours after the irritant injection (Figure 1(a)). The number of mononuclear cells significantly decreased 4 and 8 hours after glycogen injection. Conversely it was 


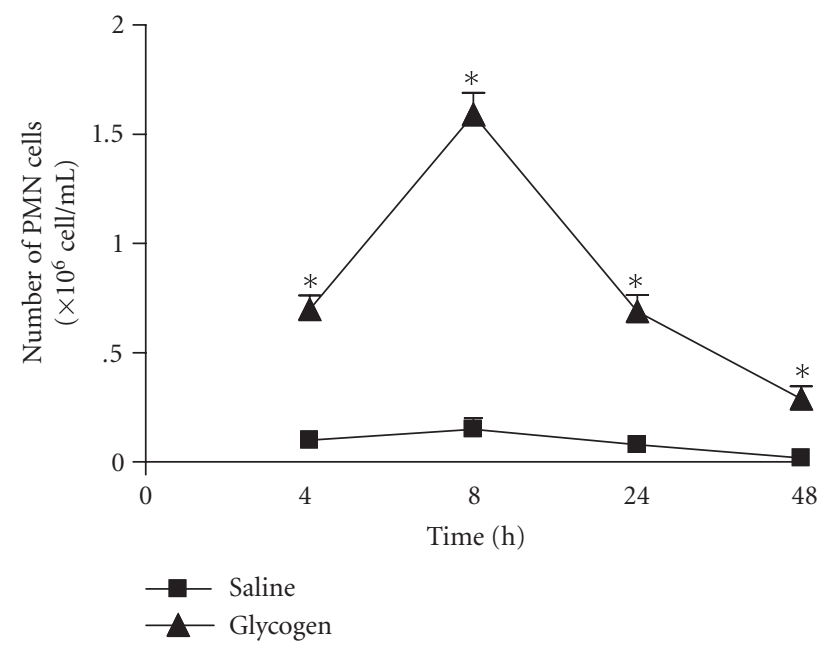

(a)

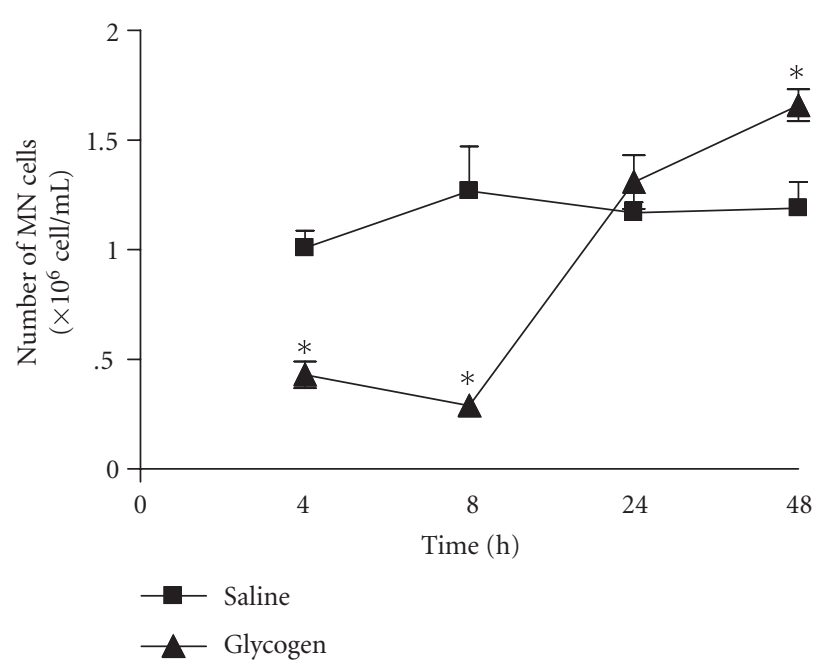

(b)

FIgURE 1: Kinetics of leukocyte influx to peritoneal cavity of mice after IP injection of a glycogen solution ( $5 \%$, $500 \mu \mathrm{L} /$ animal). Number of polymorphonuclear cells (PMN cells; (a)) and mononuclear cells (MN cells; (b)). Results are expressed in absolute numbers obtained in relation to the total number of collected cells. Values represent mean values \pm SEM for $8-16$ animals for each experimental time. ${ }^{*} P<.05$ in comparison with values obtained in control animals.

showed an increase of these cells after 48 hours of irritant treatment (Figure 1(b)).

\section{Glycogen-induced antinociceptive effect}

To confirm the antinociceptive response observed after intraperitoneal glycogen injection, we submitted the animals to the writhing test after glycogen injection. Results showed an antinociceptive effect, 4 and 8 hours after the irritant treatment, when compared with animals previously injected with saline or acetic acid alone (42 and $47 \%$ inhibition, resp.) (Figure 2). It was also observed that the injection of glycogen solution did not induce changes in the nociceptive response of animals after 24 or 48 hours of treatment when compared with control animals (Figure 2).

\section{Transference of inflammatory cell-free exudate}

To investigate if the antinociceptive factor was secreted by migrated leukocytes after the glycogen inoculation, naive animals were injected with cell-free exudate, obtained after different time intervals, and after 30 minutes evaluated in the writhing test. Results show that the transference of cell-free exudates induced antinociceptive effect when they were obtained 4 or 8 hours after glycogen injection ( 40 and $45 \%$ inhibition, resp.). The treatment of mice either with cell-free exudate obtained 24 or 48 hours after the irritant injection or with the supernatants obtained of animals injected only with saline did not influence the nociceptive response (Figure 3).

\section{Adsorption of S100A9 of the cell-free exudates with antinociceptive effect}

To investigate whether the antinociceptive effect induced by cell-free exudates obtained after 4 or 8 hours of the

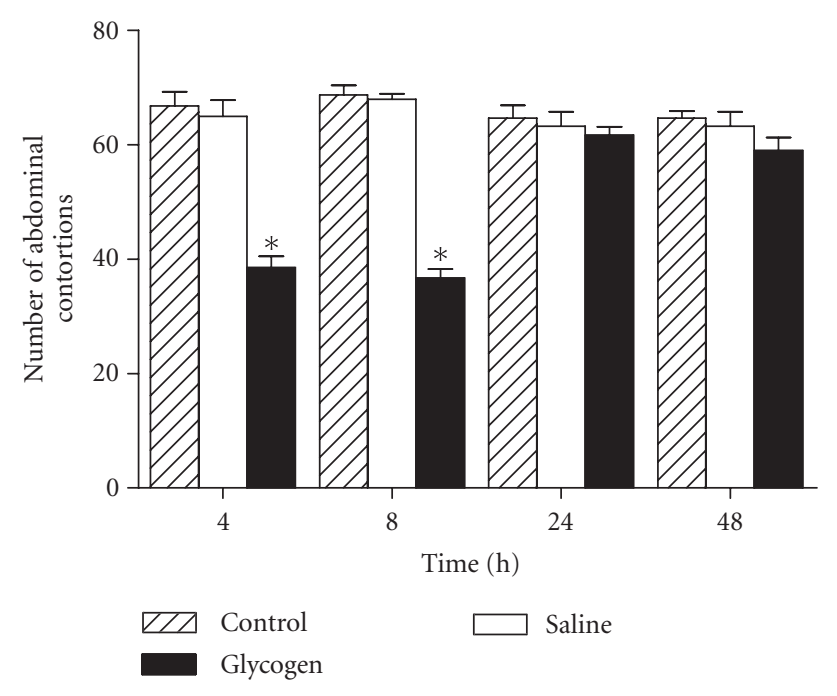

FIGURE 2: Effect of glycogen on painful sensibility of mice evaluated in the writhing test. The test was applied in different times after IP injection of glycogen $(5 \%, 500 \mu \mathrm{L} /$ animal). Controls were injected only with acetic acid. Values represent the mean \pm SEM of 8-16 animals for each group. ${ }^{*} P<.05$ in comparison with values obtained in control animals.

glycogen injection was due to secretion of the S100A9 protein, mice were treated with cell-free exudates adsorpted of this protein. Results show that adsorption of S100A9 from these supernatants, using mAb anti-S100A9 (anti-MRP-14), reverted the observed antinociceptive response (Figure 4). Treatment of animals with this mAb alone or with nonrelated rat IgG, previously to the acetic acid injection, did not alter the nociceptive response when compared with control animals (data not shown). 


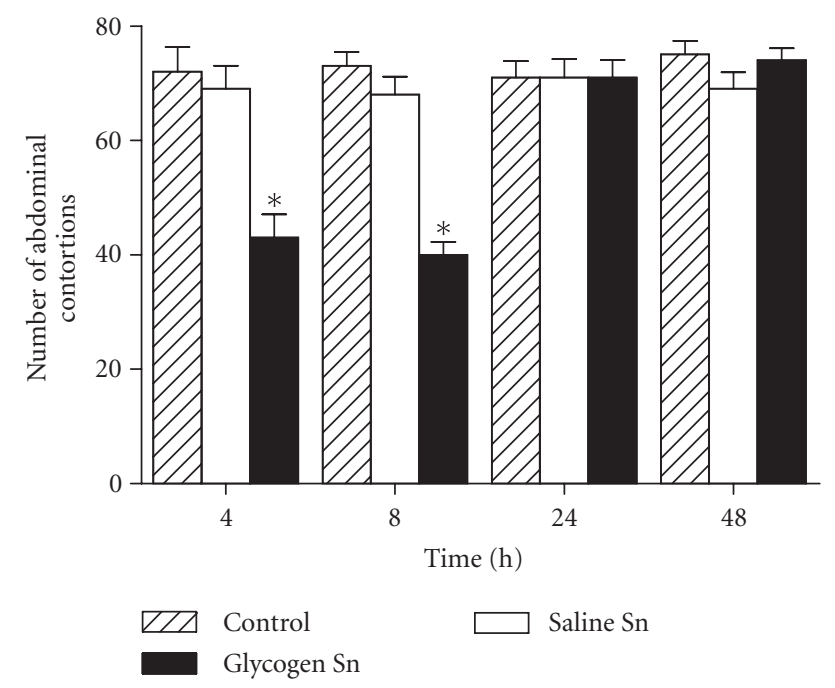

Figure 3: Effect of cell-free exudates obtained 4, 8, 24 or 48 hours after glycogen injection (Glycogen $\mathrm{Sn}$ ) in naive animals submitted to the writhing test. The exudate supernatants $(200 \mu \mathrm{L} /$ cavity) were injected 30 minutes before the test. Animals injected with supernatants obtained after saline injection (Saline Sn) were also evaluated. Controls were injected only with acetic acid. Values represent the mean \pm SEM of $8-16$ animals for each group. ${ }^{*} P<.05$ in comparison with values obtained in control animals.

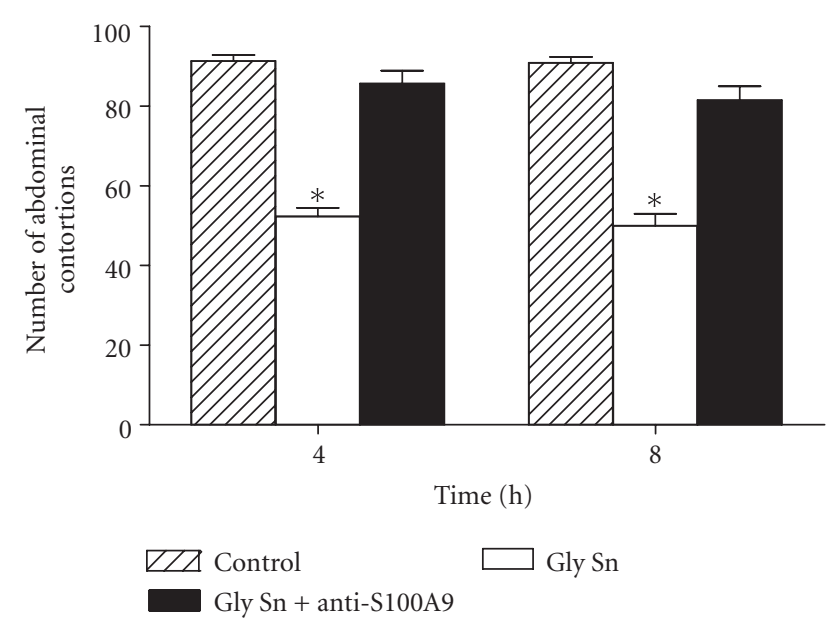

FIGURE 4: Effect of adsorption of S100A9 of cell-free exudates obtained 4 or 8 hours after glycogen injection (Gly Sn + anti-S100A9) in naive animals submitted to the writhing test. The exudate supernatants $(200 \mu \mathrm{L} /$ cavity $)$ were injected 30 minutes before the test. Animals injected with exudate supernatants not treated with $\mathrm{mAb}$ anti-S100A9 (Gly Sn) were also evaluated. Controls were injected only with acetic acid. Values represent the mean \pm SEM of 8-16 animals for each group. ${ }^{*} P<.05$ in comparison with values obtained in control animals.

\section{DISCUSSION}

Mediators secreted during inflammatory response are involved in the control of painful response. In regard to that, interleukin-4 (IL-4), IL-10, and IL-13 have the propriety of limiting the inflammatory hyperalgesia inhibiting the production of proinflammatory cytokines [32-35].

Proteins S100A8 and S100A9 comprise an important group of proteins expressed by phagocytes during inflammatory response [36], and are involved in the first line of defence against this type response [37]. The S100A9 protein, specifically, play a role in the inflammatory reaction to lipopolissacarides by inducing the release of neutrophils from the bone marrow and directing their migration to the inflammatory site, thus suggesting that it could represent a new class of early cytokines involved in innate immune responses [38].

According to the evidence suggesting that S100A9 is a proinflammatory protein [36], our group have proposed that this protein is endowed with antinociceptive activity in inflammatory pain model [24]. It was also observed the participation of S100A9 in antinociception observed during acute inflammatory peritonitis induced by glycogen or carrageenan in mice $[24,25]$. Recently, we demonstrated that the C-terminus of this protein is involved either with the antinociceptive effect on hyperalgesia induced by protease [39], or with the inhibition of the phagocytosis and spreading activities of adherent peritoneal cells [26], cells responsible by the writhing nociceptive response [27]. Based on these data, we decided to investigate if the S100A9 is secreted during glycogen-induced neutrophilic peritonitis, and if this protein directly acts in the antinociceptive effect observed in this model of acute inflammation.

A direct correlation between the number of neutrophils in the peritoneal cavity after glycogen treatment and the maximal antinociceptive response was observed, as previously described [24]. In agreement with data obtained by Pagano et al [25] our results strongly suggest that these cells could be involved in the control of inflammatory pain, possibly through S100A9 protein action.

The antinociceptive effect observed after leukocyte cellfree exudate transfer, obtained after 4 or 8 hours of glycogen injection to naive animals, confirmed that migrated cells secrete the antinociceptive factor in acute phase of inflammatory process. The demonstration that the antinociception observed was mediated by S100A9 action was confirmed by adsorption of this protein in the cell-free exudates obtained 4 or 8 hours after the irritant injection.

The participation of neutrophils in the observed antinociceptive effect, as previously shown $[24,25]$, can be reinforced by results here shown with the cell-free exudates obtained 24 and 48 hours after the glycogen injection, since they did not induce antinociception with a decrease of polymorphonuclear cells and concomitant increase of mononuclear cells.

The mechanism by which S100A9 induces antinociception was not established yet. However, taking into account that S100A9 deactivates activated macrophages [23], and that the C-terminus of S100A9 murine inhibits phagocytosis and spreading activities of adherent peritoneal cells [26], cells involved in painful response by release of hyperalgesic cytokines in the abdominal contortions model [27], the effect observed by S100A9 could be related with macrophage activation with consequent inhibition of secretion of algogenic 
factors by these cells. On the other hand, S100A9 could alter the phenotype of macrophages for an "anti-inflammatory cell" increasing the release of inhibitory cytokines, such as IL4 and IL-10, which are involved in inflammatory pain control.

Although several reports describe the presence of S100A9 in the initial phase of inflammatory response [36, 37], less is known about its biological role in nociception process. Our data strongly indicate that neutrophil-secreted S100A9 protein participates in inflammatory pain control.

\section{ACKNOWLEDGMENTS}

We are indebted to Dr Tânia Aguiar-Passeti for help with the adsorption assay. Financial support by FAPESP and Fundação Butantan is also acknowledged.

\section{REFERENCES}

[1] Schäfer BW, Wicki R, Engelkamp D, Mattei M-G, Heizmann CW. Isolation of a YAC clone covering a cluster of nine S100 genes on human chromosome 1q21: rationale for a new nomenclature of the $\mathrm{S} 100$ calcium-binding protein family. Genomics. 1995;25(3):638-643.

[2] Kligman D, Hilt DC. The S100 protein family. Trends in Biochemical Sciences. 1988;13(11):437-443.

[3] Zwadlo G, Bruggen J, Gerhards G, Schlegel R, Sorg C. Two calcium-binding proteins associated with specific stages of myeloid cell differentiation are expressed by subsets of macrophages in inflammatory tissues. Clinical and Experimental Immunology. 1988;72(3):510-515.

[4] Lagasse E, Clerc RG. Cloning and expression of two human genes encoding calcium-binding proteins that are regulated during myeloid differentiation. Molecular and Cellular Biology. 1988;8(6):2402-2410.

[5] Edgeworth J, Gorman M, Bennett R, Freemont P, Hogg N. Identification of p8,14 as a highly abundant heterodimeric calcium binding protein complex of myeloid cells. Journal of Biological Chemistry. 1991;266(12):7706-7713.

[6] Steinbakk M, Naess-Andresen C-F, Lingaas E, Dale I, Brandtzaeg P, Fagerhol MK. Antimicrobial actions of calcium binding leucocyte L1 protein, calprotectin. Lancet. 1990; 336(8718):763-765.

[7] Hogg N, Allen C, Edgeworth J. Monoclonal antibody 5.5 reacts with p8,14, a myeloid molecule associated with some vascular endothelium. European Journal of Immunology. 1989;19(6): 1053-1061.

[8] Andersson KB, Sletten K, Berntzen HB, et al. The leucocyte L1 protein: identity with the cystic fibrosis antigen and the calcium-binding MRP-8 and MRP-14 macrophage components. Scandinavian Journal of Immunology. 1988;28(2):241245.

[9] Wilkinson MM, Busuttil A, Hayward C, Brock DJ, Dorin JR, van Heyningen V. Expression pattern of two related cystic fibrosis-associated calcium-binding proteins in normal and abnormal tissues. Journal of Cell Science. 1988;91:221-230.

[10] Odink K, Cerletti N, Bruggen J, et al. Two calcium-binding proteins in infiltrate macrophages of rheumatoid arthritis. $\mathrm{Na}$ ture. 1987;330(6143):80-82.

[11] Roth J, Burwinkel F, van den Bos C, Goebeler M, Vollmer E, Sorg C. MRP8 and MRP14, S-100-like proteins associated with myeloid differentiation, are translocated to plasma membrane and intermediate filaments in a calcium-dependent manner. Blood. 1993;82(6):1875-1883.

[12] van den Bos C, Roth J, Koch HG, Hartmann M, Sorg C. Phosphorylation of MRP14, an S100 protein expressed during monocytic differentiation, modulates $\mathrm{Ca}^{2+}$-dependent translocation from cytoplasm to membranes and cytoskeleton. Journal of Immunology. 1996;156(3):1247-1254.

[13] Rammes A, Roth J, Goebeler M, Klempt M, Hartmann M, Sorg C. Myeloid-related protein (MRP) 8 and MRP14, calcium-binding proteins of the $S 100$ family, are secreted by activated monocytes via a novel, tubulin-dependent pathway. Journal of Biological Chemistry. 1997;272(14):9496-9502.

[14] Siegenthaler G, Roulin K, Chatellard-Gruaz D, et al. A heterocomplex formed by the calcium-binding proteins MRP8 (S100A8) and MRP14 (S100A9) binds unsaturated fatty acids with high affinity. Journal of Biological Chemistry. 1997;272(14):9371-9377.

[15] Sohnle PG, Collins-Lech C, Wiessner JH. Antimicrobial activity of an abundant calcium-binding protein in the cytoplasm of human neutrophils. Journal of Infectious Diseases. 1991;163(1):187-192.

[16] Nakatani Y, Yamazaki M, Chazin WJ, Yui S. Regulation of S100A8/A9 (calprotectin) binding to tumor cells by zinc ion and its implication for apoptosis-inducing activity. Mediators of Inflammation. 2005;2005(5):280-292.

[17] Yui S, Mikami M, Tsurumaki K, Yamazaki M. Growthinhibitory and apopotosis-inducing activities of calprotectin derived from inflammatory exudate cells on normal fibroblasts: regulation by metal ions. Journal of Leukocyte Biology. 1997;61(1):50-57.

[18] Kerkhoff C, Klempt M, Sorg C. Novel insights into structure and function of MRP8 (S100A8) and MRP14 (S100A9). Biochimica et Biophysica Acta - Molecular Cell Research. 1998; 1448(2):200-211.

[19] Foell D, Frosch M, Sorg C, Roth J. Phagocyte-specific calciumbinding S100 proteins as clinical laboratory markers of inflammation. Clinica Chimica Acta. 2004;344(1-2):37-51.

[20] Brun JG, Haland G, Haga H-J, Fagerhol MK, Jonsson R. Effects of calprotectin in avridine-induced arthritis. APMIS. 1995; 103(3):233-240.

[21] Delabie J, De Wolf-Peeters C, van den Oord JJ, Desmet VJ. Differential expression of the calcium-binding proteins MRP8 and MRP14 in granulomatous conditions: an immunohistochemical study. Clinical and Experimental Immunology. 1990;81(1):123-126.

[22] Newton RA, Hogg N. The human S100 protein MRP-14 is a novel activator of the $\beta_{2}$ integrin Mac-1 on neutrophils. Journal of Immunology. 1998;160(3):1427-1435.

[23] Aguiar-Passeti T, Postol E, Sorg C, Mariano M. Epithelioid cells from foreign-body granuloma selectively express the calcium-binding protein MRP-14, a novel down-regulatory molecule of macrophage activation. Journal of Leukocyte Biology. 1997;62(6):852-858.

[24] Giorgi R, Pagano RL, Amorim Dias MA, Aguiar-Passeti T, Sorg C, Mariano M. Antinociceptive effect of the calcium-binding protein MRP-14 and the role played by neutrophils on the control of inflammatory pain. Journal of Leukocyte Biology. 1998;64(2):214-220.

[25] Pagano RL, Dias MAA, Dale CS, Giorgi R. Neutrophils and the calcium-binding protein MRP-14 mediate carrageenaninduced antinociception in mice. Mediators of Inflammation. 2002;11(4):203-210. 
[26] Pagano RL, Sampaio SC, Juliano L, Juliano MA, Giorgi R. The C-terminus of murine S100A9 inhibits spreading and phagocytic activity of adherent peritoneal cells. Inflammation Research. 2005;54(5):204-210.

[27] Ribeiro RA, Vale ML, Thomazzi SM, et al. Involvement of resident macrophages and mast cells in the writhing nociceptive response induced by zymosan and acetic acid in mice. European Journal of Pharmacology. 2000;387(1):111-118.

[28] Zimmermann M. Ethical guidelines for investigations of experimental pain in conscious animals. Pain. 1983;16(2):109110.

[29] Koster R, Anderson M, de Beer EJ. Acetic acid for analgesic screening. Federation Proceedings. 1959;18:412-415.

[30] Snedecor GW. Statistical Methods. 4th ed. Ames, Iowa: State University Press; 1974.

[31] Duncan DB. Multiple range and multiple F tests. Biometrics. 1955;11:1-42.

[32] Cunha FQ, Poole S, Lorenzetti BB, Veiga FH, Ferreira $\mathrm{SH}$. Cytokine-mediated inflammatory hyperalgesia limited by interleukin-4. British Journal of Pharmacology. 1999;126(1): 45-50.

[33] Poole S, Cunha FQ, Selkirk S, Lorenzetti BB, Ferreira SH. Cytokine-mediated inflammatory hyperalgesia limited by interleukin-10. British Journal of Pharmacology. 1995;115(4): 684-688.

[34] Lorenzetti BB, Poole S, Veiga FH, Cunha FQ, Ferreira $\mathrm{SH}$. Cytokine-mediated inflammatory hyperalgesia limited by interleukin-13. European Cytokine Network. 2001;12(2):260267.

[35] Saade NE, Nasr IW, Massaad CA, Safieh-Garabedian B, Jabbur SJ, Kanaan SA. Modulation of ultraviolet-induced hyperalgesia and cytokine up regulation by interleukins 10 and 13 . British Journal of Pharmacology. 2000;131(7):1317-1324.

[36] Roth J, Vogl T, Sorg C, Sunderkötter C. Phagocyte-specific S100 proteins: a novel group of proinflammatory molecules. Trends in Immunology. 2003;24(4):155-158.

[37] Nacken W, Roth J, Sorg C, Kerkhoff C. S100A9/S100A8: myeloid representatives of the $\mathrm{S} 100$ protein family as prominent players in innate immunity. Microscopy Research and Technique. 2003;60(6):569-580.

[38] Vandal K, Rouleau P, Boivin A, Ryckman C, Talbot M, Tessier PA. Blockade of S100A8 and S100A9 suppresses neutrophil migration in response to lipopolysaccharide. Journal of Immunology. 2003;171(5):2602-2609.

[39] Dale CS, Gonçalves LRDC, Juliano L, Juliano MA, Moura Da Silva AM, Giorgi R. The C-terminus of murine S100A9 inhibits hyperalgesia and edema induced by jararhagin. Peptides. 2004;25(1):81-89. 


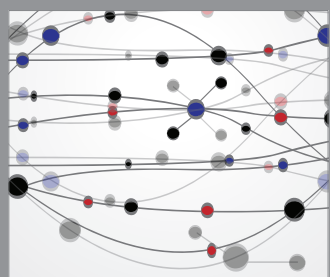

The Scientific World Journal
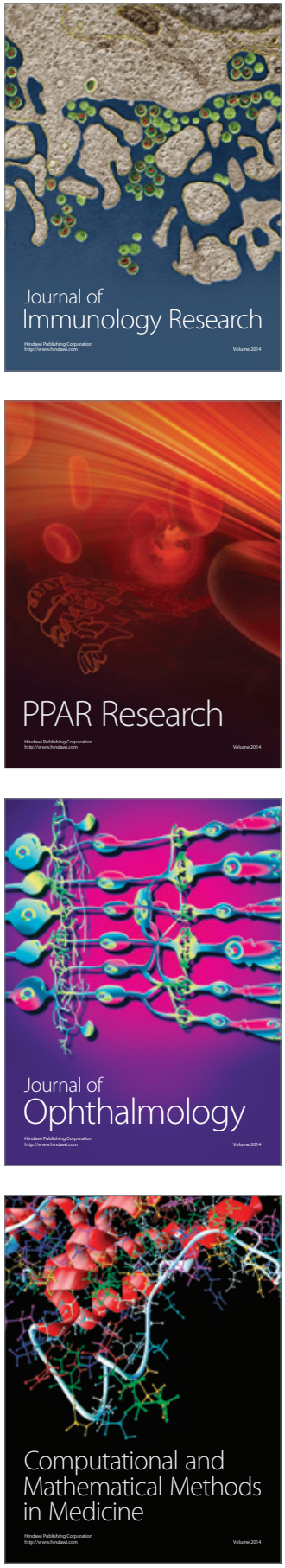

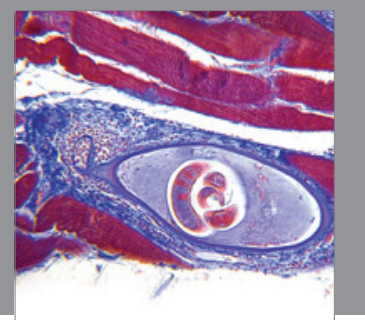

Gastroenterology

Research and Practice
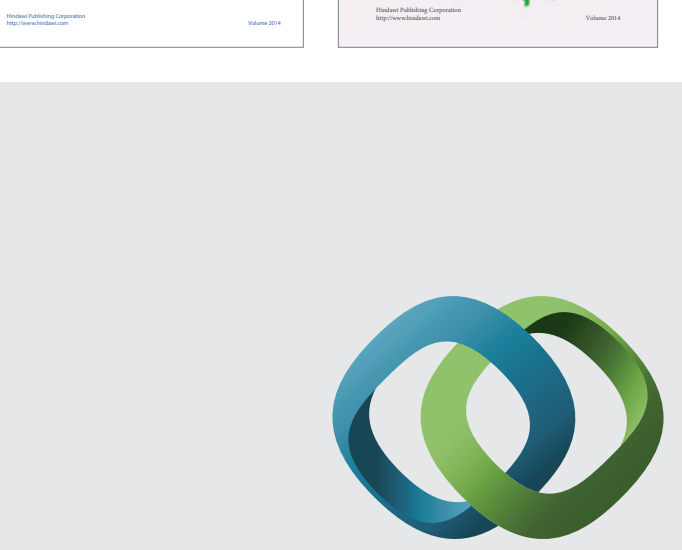

\section{Hindawi}

Submit your manuscripts at

http://www.hindawi.com
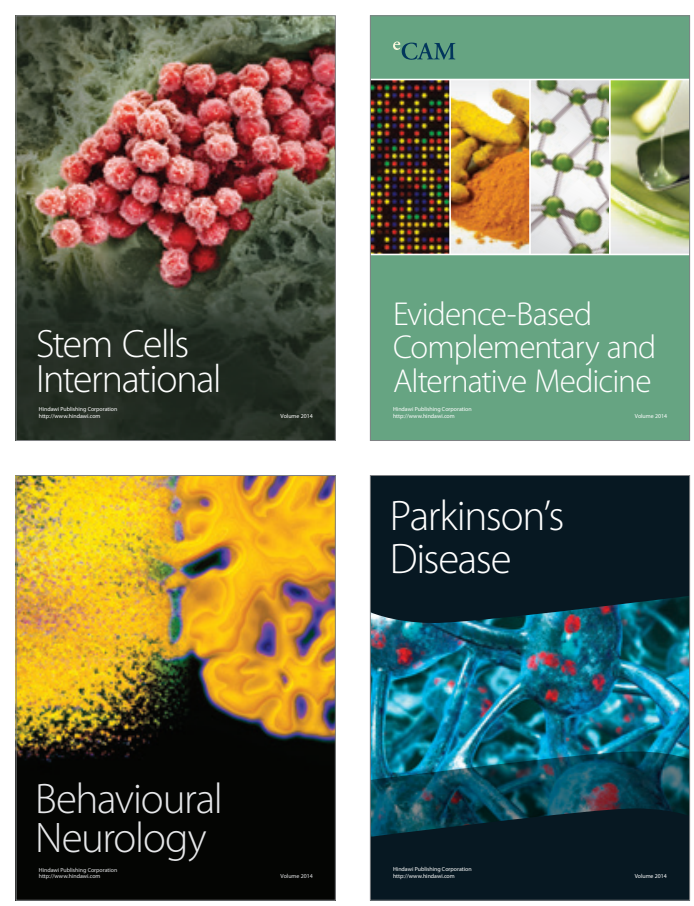

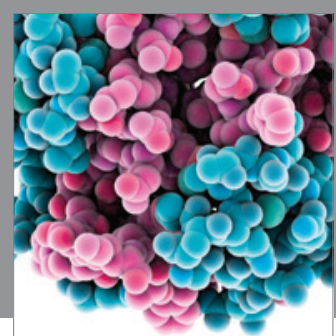

Journal of
Diabetes Research

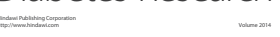

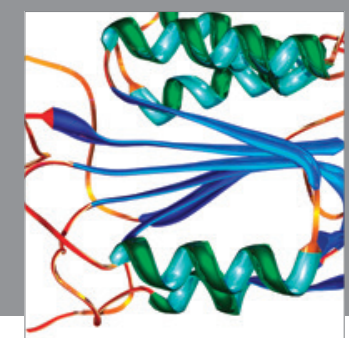

Disease Markers
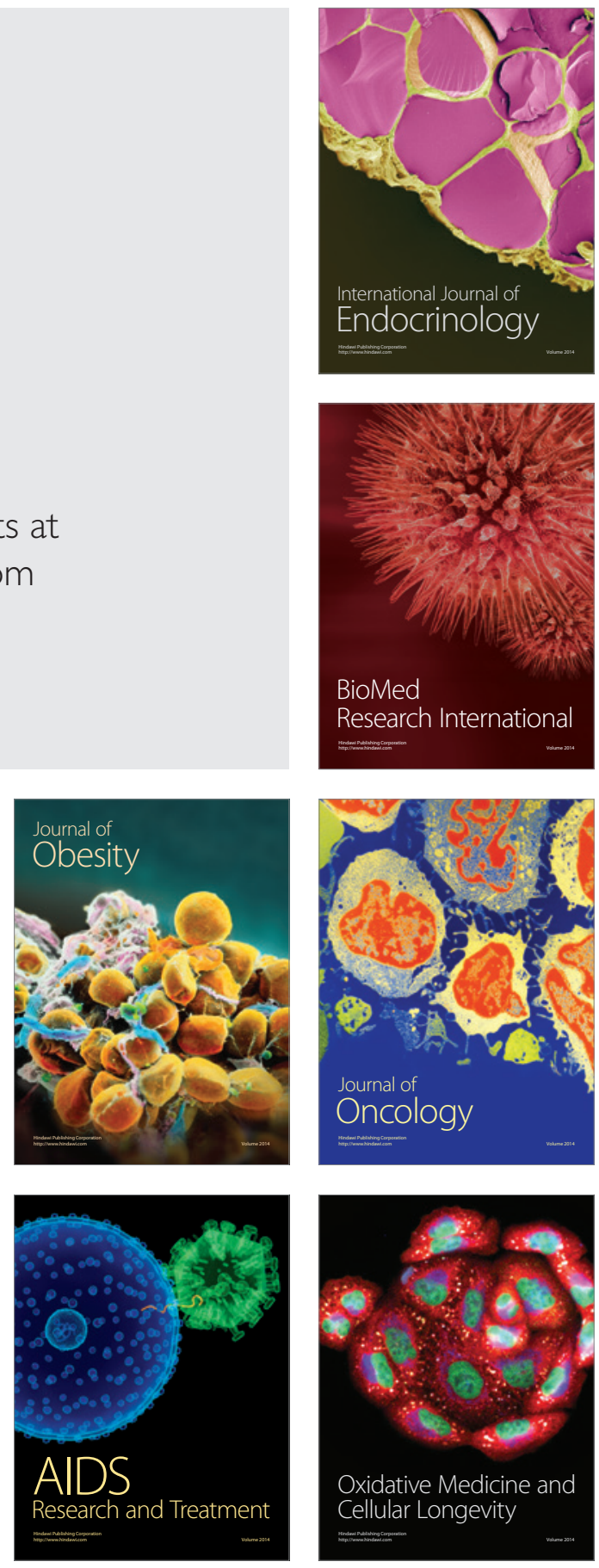